\title{
Research on Design Innovation for Reshaping Local Cultural Characteristics of the Tourist Souvenirs
}

\author{
Qiao Yang ${ }^{1}$ \\ ${ }^{1}$ Design Art and Media School, Nanjing University of Science and Technology, 21009, Nanjing, China
}

\begin{abstract}
This article traces the essence of the tourist souvenir design, explaining the core of its value, the essence of local culture, and emphasizing the law of souvenir market value that maintains the uniqueness of local culture to attract purchases. By analysing the current situation of design homogeneity and lack of innovation in Chinese market, it proposes an innovative idea, "Back to Design Origins". Then taking Nanjing souvenir design as an example, it introduces two innovative approaches, "Discovery and Application of New Cultural Elements" and " Cute Stylization of Traditional Symbols". In the end, it summarizes several feasible rules on element selection, symbolic method application, and carrier selection, mainly based on the thought of "Back to Design Origins".
\end{abstract}

\section{The essence of the tourist souvenir design}

Local traditional culture is an overall representation of the evolution and integration of a local civilization that reflects the characteristics of the region and incorporates various ideological cultures and ideologies of local history [1]. Tourist souvenirs can best reflect the most fundamental cultural characteristics of a resort or a city, showing particularity and irreplaceability.

Tourist souvenirs are products purchased by tourists in tourism, which are rich in regional folk customs and cultural characteristics, and have memorable values. Its sales and promotion is a process of disseminating local characteristics and culture. Excellent souvenirs can not only drive local economic benefits but also protect and inherit many culture-loaded items.

Tourist souvenir design is actually a process of symbolizing local cultural elements [2]. The stronger the cultural characteristics of souvenirs, the more attractive they are to tourists, with a great desire to buy. It further illustrates that souvenirs with stronger cultural characteristics have higher market value.

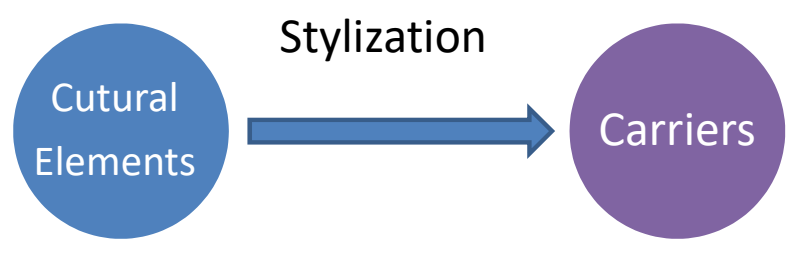

Figure 1. Souvenir Design, a stylization

\section{The situation of Chinese souvenir market}

Nowadays, although the tourist souvenir markets in various places have greatly increased in scale with the development of society, the quality and innovation of souvenirs have not improved simultaneously. Take Beijing as an example. In 2009, 187 scenic spots in Beijing received more than 150 million tourists, a yearon-year increase of $29.8 \%$, and the sales revenue of goods was 140 million Yuan, a year-on-year increase of $15.9 \%$; Obviously, compared with the rapidly growing number of tourists, the lag in the development of tourism commodities has become one of the important factors affecting the development of Beijing's tourism industry [3]. The situation in other tourism cities is even unpromising. What exactly causes the current dilemma in China's urban souvenir market?

\subsection{Design homogeneity, lack of characteristics}

There is a serious design homogeneity problem in the Chinese souvenir market. We can see a large number of similar tourist goods in various cities. Because there are no distinctive local cultural characteristics, these products completely lack the unique core value of culture, which also makes tourists lose desire to buy, leading to a continued downturn in the market.

\subsection{Single approach, lack of pleasant innovation}

Due to a lack of innovation, many souvenirs use unchanged models over the years. Many souvenir

\footnotetext{
*Corresponding author: e-mail: mikejoe88@126.com
} 
packages still use very old cartons and plastic packaging [4]. The traditional style of design has lost its lasting appeal, and the cultural characteristics of souvenirs have gradually lost their former halo.

With the development of the times, people's aesthetic taste has changed tremendously, and there are more expectations for new colour, style and packaging of souvenirs. For example, the refrigerator sticker with the Egyptian pharaoh's head not only meets the requirements of tourists for unique cultural experience, but also meets their potential needs for functional souvenirs, such as interior decoration, multifunction, small and portable, etc.

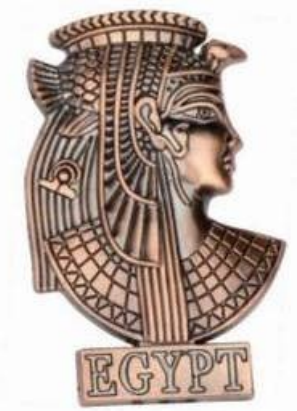

Figure 2. Pharaoh Refrigerator stickers

However, the connotation of this cultural identity in souvenirs has gradually weakened or even lost because of the following two main reasons. On the one hand, cultural elements selected in designing are limited to the traditional historical and cultural items which are too familiar to everyone without any surprises. On the other hand, single and rigid symbolic approaches make the souvenirs completely lose their attraction to tourists. As a result, consumers lose their desire to buy.

\section{The exploration back on the origin of regression design}

According to the analysis above, the generalization souvenir market with no clear segmentation, the homogeneity of design, and outdated styles are three major reasons for the weakening or lack of the value of souvenir's intrinsic cultural traits. It can be seen that strengthening the intrinsic cultural essence and attracting purchases is the fundamental solution to maintain the value of souvenirs. Therefore, we return to the origin of design and seek innovative concepts through effective and reasonable means. According to the process of designing souvenirs shown in Figure 1, by rethinking "cultural elements", "symbolization methods" and "carriers", several feasible innovative methods are explored to enhance souvenirs' cultural characteristics and stimulate consumption growth.

\subsection{New cultural elements discovered from timeline}

The cultural connotation of souvenirs refers to the overall representation of the evolution and integration of a certain local civilization, which reflects the characteristics of the region and integrates various ideological cultures and ideologies of local history [5]. In a general sense, it refers to various representative cultures that have been produced in different historical periods far away from today. Taking Nanjing souvenirs as an example, most of the cultural elements they contain originate from the Republic of China, Qing Dynasty, Ming Dynasty and other earlier historical dynasties.

However, from the analysis of the definition of tourist souvenirs, it can be concluded that the time range of the cultural characteristics of tourist souvenirs should include not only the relative historical periods in past, but also the current time and the period closer to the present. Therefore, discovering and applying new cultural elements emerging in modern time will increase the innovation of local souvenirs.
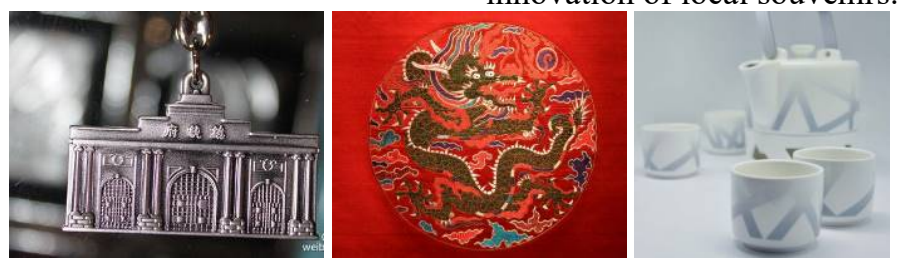

Figure 3. Presidential Palace pedant, Ming dragon brocade, Bird's Nest teapot design

How to find and apply new cultural elements can get inspiration from the concept of cultural connotation of souvenirs, which is summarized as special things, people or events that appear in special time periods. Among all these "things", landscapes and architectures are more visually unique and intuitive, easier to identify. Therefore, they became representatives of the new culture of the city, recognized by both tourists and local people. In addition, compared to other things, their unique shapes are more suitable as a reference for souvenir design, especially as a reference for shape design.
In 2005, the "Jinling Evening News" initiated the "New Jinling 48 Scenic Spots" selection campaign. After the selection, Shanling, Ming Xiaoling, Nanjing Yangtze River Bridge, Yuejiang Tower, Yunjin Museum, Fu Jiabian Modern Agricultural Ecological Park, etc. The old and new attractions in Nanjing have become the "48 new scenic spots of Jinling" in the 21st century [6].

Among all the new scenic spots, the Nanjing Yangtze River Bridge, commonly known as the "One Bridge", is the most distinctive. It is the first double-layer railway and highway bridge designed and constructed by China on the Yangtze River; it is of great significance in the 
history of Chinese bridges and is an important milestone in Chinese bridge construction [7]. This iconicity makes it a new characteristic of Nanjing's urban culture, which in turn makes it the most representative cultural element in the innovative design of Nanjing souvenirs.
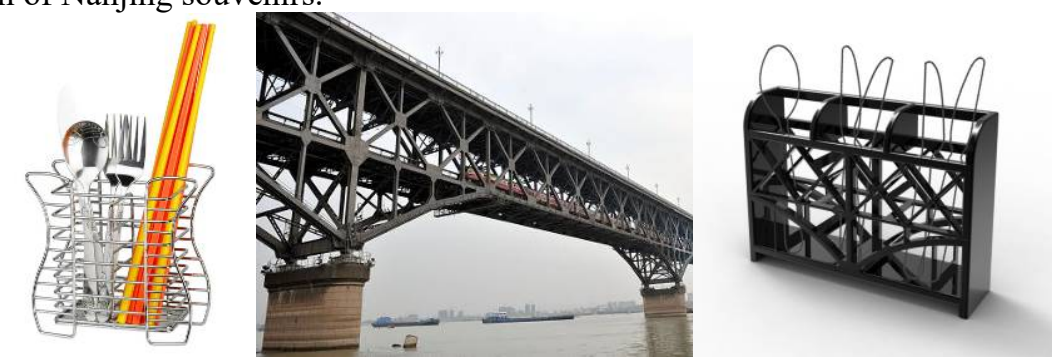

Figure 4. Nanjing Yangtze River Bridge and its Kitchen Chopstick Storage Basket

\subsection{A new attempt of traditional symbols: cute stylization}

Undoubtedly new design applied the latest fresh elements brings fresh visual enjoyment to consumers. However, it is difficult for traditional elements to obtain such amazing changes according to similar ideas and methods, because people want to keep the traditional image recognized by the public, but at the same time hope to obtain enough freshness to keep attractions to tourists.

Although many souvenirs retain the characteristics of traditional culture, unchanging design makes them extremely outdated, which cannot catch the attention of modern customers. Even though it may attract consumers by low price to some extent, such strategy eventually makes the situation worse.

In order to solve this dilemma, design will start from the perspective of element symbolization, which mainly changes the visual image of traditional cultural symbols on souvenirs and reshapes it with popular styles. Taking the souvenir of Nanjing Ming Palace as an example, the following describes the details of the application of Cute Stylization.

\subsubsection{The concept of Cute.}

"Meng" in Chinese means Cute in English, which also means "to be attractive in a pretty or endearing way" [8]. Facing faster and faster modern life, people increasingly like such humorous but empathetic style. It allows people to experience happiness while relaxing without the stress of life. Through applying this cute stylization for traditional cultural elements, many traditional souvenirs

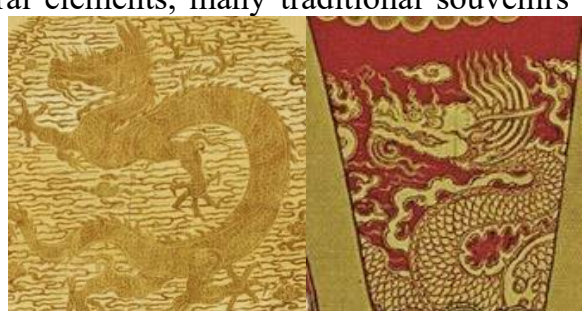

The new tourist souvenir design takes advantage of the structural similarity between the Nanjing Yangtze River Bridge and the kitchenware storage rack.

once again once again exude vitality and attract tourists as before.

\subsubsection{Ming dragon pattern.}

Nanjing was the founding capital of the Ming Dynasty, so it has a strong imprint of Ming royal culture. Local souvenirs, such as traditional clothes, home accessories, and handicrafts, mainly use Ming royal elements. The dragon is a symbol of ancient Chinese emperors. Ming dragon pattern on the emperor's clothing has distinguished characteristics from others. With the development of the Ming Dynasty, the dragon pattern also changed and it has its own characteristics in different stage. In the early Ming Dynasty, the dragon pattern inherited Song and Yuan style. Most of the shapes were sideways, the mouth of the dragon was closed, and the mane was flying upwards. The shape of the dragon was slender, and its four claws were strong. In the middle Ming Dynasty, the entire empire entered a relative stable period. The dragon was roughly similar to the early style, with still thin and elongated body, but its mouth had been opened, making the expression richer and more personality. In the late Ming Dynasty, the country has entered a relatively prosperous era. From nobles to original people all pursued enjoyment and preferred hilarious items. At this time, the proportion of dragon heads increased and the expression was lively, giving people a joyful feeling [9]. In this case, the dragon of the late Ming Dynasty was chosen because it was lively and humorous, and more harmonious in design, making Cute Stylization applied easier. In addition, it simplifies the design process of element symbolization and reduces possible image-transform problems, such as the loss of culture characteristics.
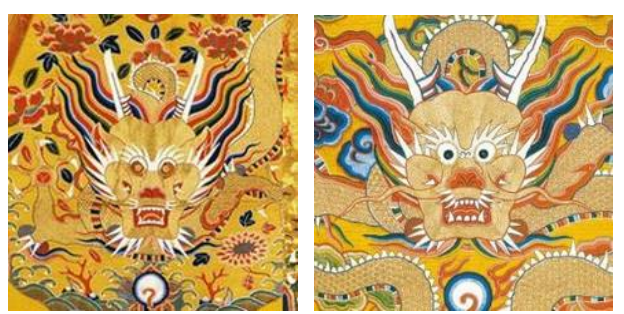

Figure 5. Ming dragon in the early, middle, late period 


\subsubsection{The process of cute stylization of symbols.}

One basic method of Cute Stylization is to change the proportion of each part of the reference element, such as enlarging head while reducing body, or changing all parts at the same time. The alarm clock is selected as first carrier, because it is similar to the short body in terms of shape. When designing, the dragon head is transplanted directly to the bell body and the dragon feet can be used as supporting members. The clock face uses two options. The first scheme uses the traditional time panel. Without affecting the timing observation, the dragon's eyes, nose and beard are drawn on the glass cover with a white outline drawing method to bring the faucet to life. The other scheme uses electronic timing. The panel, above the timing area with large dragon eyes, vividly conveys the joy of the prototype pattern.

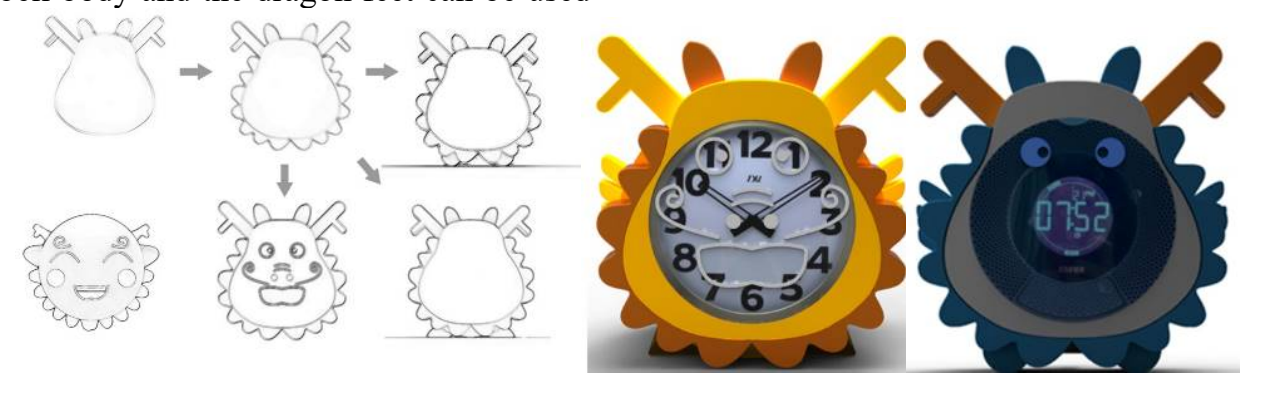

Figure 6. Dragon Pattern in design evolution

\section{Conclusion}

Through the above practical research, the following innovative ideas and practical guidelines for the design of urban souvenirs are summarized.

\subsection{Discover new cultural elements on timeline}

Discover design elements along the local historical timeline, especially new cultural elements that are constantly emerging in the modern history period.

The elemental exploration time range described in the Nanjing Souvenir Design Case is mainly from the decades after the founding of the People's Republic of China to the present. In the subsequent innovation process, the time range for new element exploration will shift backwards with time. Therefore, continuous attention to the new iconic cultural elements that have emerged in subsequent times can find new breakthroughs in the innovation of urban souvenirs.

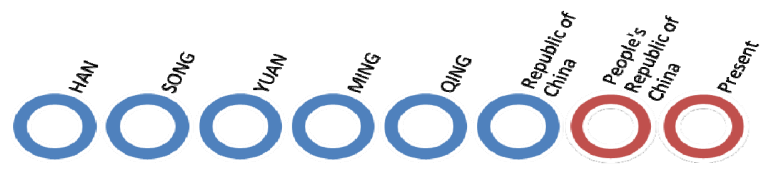

Figure 7. Timeline

\subsection{Representative landmarks or buildings in the new era}

Architecture and landscape have typical visual characteristics of local culture, especially showing distinctive features in a particular age, which make them more easily recognized by tourists than other elements. Their intuitive forms make them easier for symbolization as reference elements. Therefore, in design exploration for new elements, it prefers for the latest emerging representative architectures and iconic landscapes.

\subsection{Style changing of traditional cultural symbols}

No matter which symbolization method is chosen, the core principle is to retain the most fundamental characteristics of cultural elements. If this trait disappears, the core cultural characteristics of souvenirs will also disappear, and buyers will lose their interest in buying. However, the intrinsic cultural value of traditional souvenirs has gradually weakened with the internationalization of the tourism industry. The fundamental reasons are the current state of fast consumption, the increasingly changing aesthetic taste of consumers, and the diversification of tourist souvenir consumer groups. The main method to reshape the intrinsic value of traditional symbolic cultural characteristics is to learn from the current fashion trends, cater to consumers' tastes (especially young people), and develop design innovations based on styles, so that traditional souvenirs emit a new charming charm.

\subsection{Adaptation of elements to symbolization and carriers}

The element and the symbolization method must be adapted in form or style to ensure that the element can be symbolized quickly and the successful conversion of materialization can be achieved. Moreover the symbolic design of the carrier fully considers the mutual adaptation and adjustment between materials, structures and shapes, so as to maintain the complete display of the original cultural element characteristics as much as possible.

All in all, the fundamental purpose of the design of souvenirs is to activate the core value of souvenirs-the cultural characteristics of their connotations, and to maintain their continued appeal to consumers. While shouldering the heavy responsibility of inheriting local 
culture, designers need to actively explore history, study history and culture, grasp the lifeblood of the times, and meet consumer needs.

\section{References}

1. Shi, Y.T. (2009) Introduction to Chinese Traditional Culture. Xueyuan Publishing House, Beijing.

2. Huang, H.S., Sun, H.Y. (2006) Design Principle. Southeast University Press, Nanjing.

3. Gu, Y., Shen, Z.J., Xia, Q.X. (2011) How to make up for the shortcomings of the tourist souvenir market?. http://city.sina.com.cn/travel/t/2011-0304/084614987.html.

4. Yang, C.F., Yao, X.G. (2003) Exploration of the Ways of Tourist Souvenirs Development. Journal of Southern Yangtze University (Humanities \& Social Sciences), 3-2: 117-119.
5. Shi, Y.T. (2009) Introduction to Chinese Traditional Culture. Xueyuan Publishing House, Beijing.

6. Nanjing Newspaper Network. (2005) Jinling Evening News "New Jinling 48 Scenic". http://news.sina.com.cn/o/2005-0413/10195637171s.shtml

7. Xiaoxiang Morning News. (2014) Nanjing Yangtze River Bridge completed and opened to traffic. http://epaper.xxcb.cn/xxcba/html/201410/12/content_2809465.htm

8. Zhang, Z.H., Huang, L.H. (2006) the Influence of Cute Culture on Product Design Style. http://dolcn.com/data/cns_1/article_31/paper_311/pi nd_3111/2006-04/1145196551.html

9. Dong, J. (2012) Dragon Robe on the Battle_-The Use of High-grade Clothing Patterns in Ming Dynasty. Market Weekly (Art Finance), 7:153-159. 